Article

\title{
Systematic Development of Sustainability-Oriented Cyber-Physical Production Systems
}

\author{
Christopher Rogall ${ }^{1, *}$, Mark Mennenga ${ }^{1}$, Christoph Herrmann ${ }^{1,2}$ and Sebastian Thiede ${ }^{3}$ (i)
}

1 Chair of Sustainable Manufacturing and Life Cycle Engineering, Institute of Machine Tools and Production Technology (IWF), Technische Universität Braunschweig, Langer Kamp 19b, 38106 Braunschweig, Germany; m.mennenga@tu-braunschweig.de (M.M.); c.herrmann@tu-braunschweig.de (C.H.)

2 Fraunhofer Institute for Surface Engineering and Thin Films (IST), Bienroder Weg 54 E, 38108 Braunschweig, Germany

3 Chair of Manufacturing Systems, Department of Design, Production and Management, Faculty of Engineering Technology, University of Twente, De Horst 2 (Building 20), 7522 LW Enschede, The Netherlands; s.thiede@utwente.nl

* Correspondence: c.rogall@tu-braunschweig.de

Citation: Rogall, C.; Mennenga, M.; Herrmann, C.; Thiede, S. Systematic Development of Sustainability-

Oriented Cyber-Physical Production Systems. Sustainability 2022, 14, 2080. https://doi.org/10.3390/su14042080

Academic Editor: Wen-Hsien Tsai

Received: 15 December 2021

Accepted: 7 February 2022

Published: 11 February 2022

Publisher's Note: MDPI stays neutral with regard to jurisdictional claims in published maps and institutional affiliations.

Copyright: (C) 2022 by the authors. Licensee MDPI, Basel, Switzerland. This article is an open access article distributed under the terms and conditions of the Creative Commons Attribution (CC BY) license (https:// creativecommons.org/licenses/by/ $4.0 /)$.

\begin{abstract}
Manufacturing companies increasingly have to address the risks and contributions related to their environmental impacts. Therefore, more data are needed in order to provide full transparency with regard to production, and to highlight the potential relationships between the process data and the environmental impacts. In order to achieve this data transparency, targeted digitalization is needed that is tailored to the goal of reaching minimized environmental impacts. Cyber-physical production systems (CPPSs) are central for the digitalization of manufacturing. However, they may also come with an initial environmental backpack. Due to unawareness of relevant interdependencies when setting up CPPS, data may be collected which is not helpful or necessary for the development of sustainability-oriented CPPS. Therefore, a critical assessment is required which data is necessary to support sustainable manufacturing and to avoid unreflective data collection. This requires the identification of the relevant factors and their interdependencies within the context of sustainability in production. By identifying the influencing factors, the measurement strategy can be linked to the appropriate sensor technologies that explicitly contribute to the target fulfillment. The design of more sustainable data structures using a cross-impact analysis is illustrated in this paper as a generic methodological approach, which will be applied to a 3D-printing use case.
\end{abstract}

Keywords: sustainable cyber-physical production systems; environmental impact in manufacturing; parameter analysis

\section{Introduction}

Increasing demands for environmental sustainability provide new challenges for the manufacturing sector $[1,2]$. Companies are required to become more accountable for their contributions and risks related to environmental sustainability $[2,3]$. Therefore, increased transparency with regard to their environmental performance is needed. This requires a high volume of data from manufacturing companies that allows identifying correlations between the process data and the resulting environmental impacts of the manufacturing processes. This is where the digitalization of manufacturing becomes more relevant.

The digitalization of manufacturing can be a means of supporting transparency with regard to the process data, and it can allow the identification of potential areas for improvement. In general, the digitalization of manufacturing is commonly referred to as "Industry $4.0^{\prime \prime}$, which was introduced in the high-tech strategy of the German Federal Government in 2012 and is related to the Fourth Industrial Revolution [4]. It is mainly based on the use of cyber-physical systems (CPSs) [5,6]. CPSs describe real-time digitalized systems with physical components, and they consist of systemic layers that can communicate with each 
other [7]. In the production context, these CPSs are further developed into cyber-physical production systems (CPPS) [8]. CPPSs consist of physical components (e.g., machines and sensor technology), the data processing, the respective virtual cyber components (data analysis, simulations, digital twins), and a decision support, or control, element [8]. The levels of a CPPS are networked via humans at the center of consideration and, similar to the CPS, they are in communication with each other [8].

CPPSs have proven that they can contribute positively to the sustainability of a production system [8-10]. However, CPPSs are also connected with an initial environmental backpack that, because of the sensors and IT components integrated into the system, can have a negative impact on the environmental performance [9]. Thus, increased transparency and a deeper understanding of the production processes are not necessarily associated with greater sustainability. Rather, it is necessary to assess each digitalization measure and the process factors with regard to their positive and negative impacts on sustainability. Therefore, the environmental backpack of a CPPS should be considered and should be determinable at the start of the planning process for a digitized manufacturing system.

So far, there is no acknowledged definition for sustainability-oriented CPPSs. In this elaboration, they refer to CPPSs that aim to make production processes more sustainable through the use of CPSs, where the use of CPSs in the production environment should be beneficial and should take into account all of the impacts along the lifecycle of the CPPS.

In order to support the development of sustainability-oriented CPPSs, it is necessary to identify only those parameters and data that have the most decisive influences on sustainability. In this way, CPPSs can be configured in such a way that the environmental backpack is minimized. To date, it is not sufficiently known how to identify these parameters, datasets, and measures to generate meaningful value in the context of sustainable production. Thus, it is necessary to determine which factors of the CPPS have increased impacts on the sustainability of production systems.

Given this problem, the aim is to enable the controlled and systematic development of sustainability-oriented cyber-physical production systems. The development of a methodical approach as a framework for this problem is in focus. As an instrument within the framework, the cross-impact analysis is used to identify the relevant parameters and their relations to the goals of the environmentally sustainable and systematic development of CPPSs. Through the identification of the parameters, the appropriate measurement strategies can be developed, which are directly related to the sensors and measurement elements that explicitly contribute to the goal fulfillment.

In this paper, the foundations of CPPSs and sustainable development are first introduced. This is the basis for presenting the state of the research and for deriving the requirements for this approach. Thereafter, the methodological framework is presented and explained in more detail, and it is then applied to a case study that is an exemplary illustration of the methodological framework for the application field of 3D printing.

\section{Theoretical Background}

In order to create a high level of information transparency in terms of the environmental performance of manufacturing systems, information on the relationship between the process parameters and the resulting environmental impact from manufacturing is required. This information can then be used to derive the measures for the process optimization, and it can be communicated to machine operators via assistance systems or used for direct plant control $[2,11]$. To acquire this information, sustainability-related data needs to be gathered from all of the relevant process steps, which can support different objectives, such as increasing the economic and environmental performances of a manufacturing machine system. The following sections describe how CPPSs can contribute to the attainment of this goal. In Section 2.1, a reference is made to the theoretical foundations of CPPSs. Section 2.2 briefly introduces the need to take a comprehensive view of the sustainability of CPPSs. On the basis of this, the state of the research is presented with regard to the development of sustainability-oriented cyber-physical production systems, which sets the basis for the defi- 
nition of the research gap, as well as the requirements for a new methodological approach to close this gap.

\subsection{Cyber-Physical Production Systems}

Cyber-physical systems are systems with computational and physical features [12]. These can interact with each other, and they are in contact with humans via various communication channels [12]. The introduction of a CPS in the production context refers to the already introduced cyber-physical production systems. In CPPSs, the physical components always face the virtual environments and are linked via data acquisition and control, or visualization (Figure 1) [8,9,13,14].

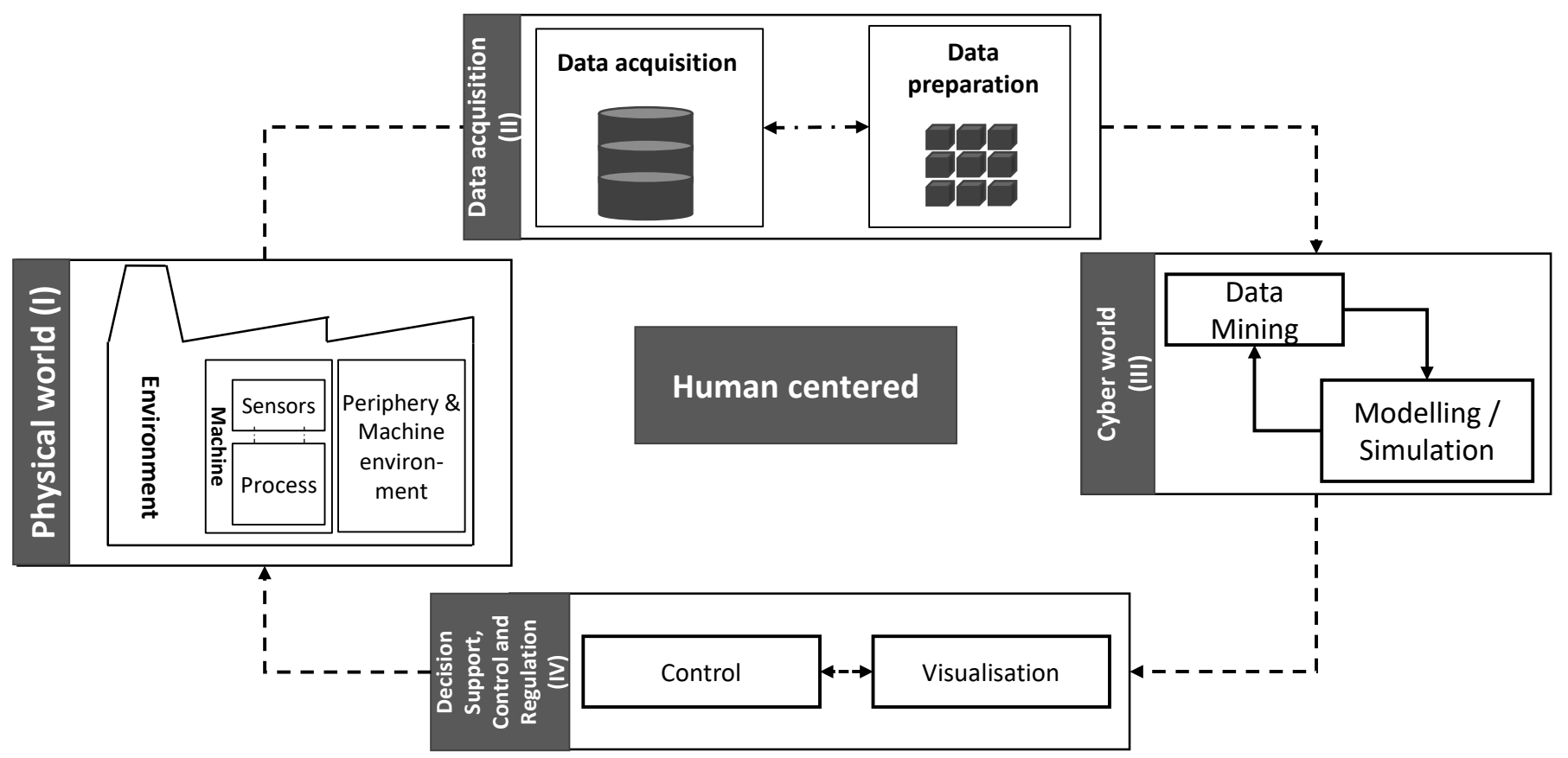

Figure 1. Schematic cyber-physical production system $[8,9,14]$.

The "physical world" (I) of the CPPS is based on the equipment of the production system. Sensor systems or process parameters are used to generate data. Parameter controls are used to define the generic CPPS, and the relationships to the state and disturbance variables are established. The data generated by the physical layer are described under "data acquisition" (II). At this stage of a CPPS, the consolidation, with respect to the data preparation and the storage of the data, takes place. Database systems are used to manage the data. The "cyber world" (III) uses this processed data and executes the modeling and simulation (e.g., the data mining or the machine learning approaches) in order to be able to generate methodically substantiated solutions and recommendations for data-driven or knowledge-based actions. By transparency creation and action development, the processstructure-property change relationships are captured and improved. The solutions and results that are elaborated can be recorded and visualized under the last section of the cycle, which is the decision support, or the control and regulation (IV). The decision support correlates with the visualization of the resulting measures and improvements of the system through the help of the data processing of the previous sections of the CPPS. In this context, the control of the physical level on the basis of the knowledge gained from the cyber level is the key to a CPPS. The human being remains at the center of a CPPS, e.g., through visualization, and, in the case of more profound processes, through the control $[8,9,13,14]$. 


\subsection{Environmental Sustainability in CPPSs}

The objective of this paper is the design of an industrial CPPS through a digital solution to support the improvement of the environmental performance of a manufacturing system in the long term. Therefore, the evaluation of the CPPS in terms of environmental sustainability was an important component of this $[8,15]$. To this end, the environmental impact (EI) of the (additional) digital solution needs to be considered. Figure 2 schematically shows the environmental impact of this newly introduced digital solution in a manufacturing system [15].

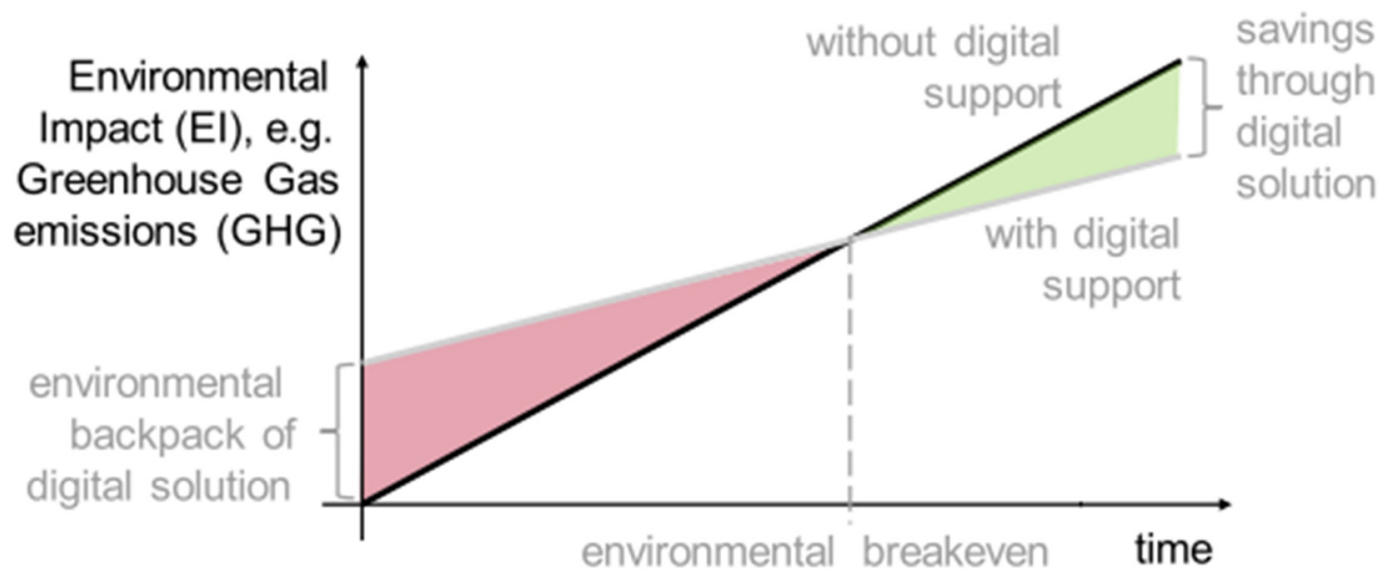

Figure 2. Environmental impact of digital solution in a CPPS [15].

Because of the "environmental backpack" resulting from the manufacturing of digital solutions, CPPSs must always be viewed critically in sustainability-oriented production. It should be possible to reach a breakeven point over time so that an initially negative influence transforms into a saving of emissions, resulting in a net positive impact. Thus, only then it is suitable to introduce a digital solution in manufacturing systems $[8,15]$.

Support for the environmental sustainability of digital solutions and CPPSs can be provided by targeted simulations that are closely linked to the factory model and the plans of the company [16]. The simulations can support the prediction and improvement of the sustainability performance of a company [16]. However, the potential negative environmental impact also needs to be considered here, since, in this case too, the hardware and technology introduced must first be examined with regard to the environmental impact, e.g., the energy consumption of the simulations.

Finally, when considering sustainability-oriented CPPSs, the data structure and processing are crucial. The data structures and the tracking of the data are essential in order to ensure an efficient and secure exchange within a production system [17]. For real-time data processing and decision support, as is required in a CPPS, transparent and traceable parameters and data histories are needed with respect to the environmental performance of the system [17].

For a sustainability-oriented CPPS, the decisive factors are not only the hardware that is introduced into the manufacturing system, but also the data and the processing, which play important roles.

\subsection{State of Research}

The literature in the area of sustainability-oriented cyber-physical production systems reflect the complexity of the systematic and sustainable development of Industry 4.0, or digital solutions. While Industry 4.0 solutions are directly subject to the challenges of sustainable and efficient material and resource use, the fundamental environmentally sustainable nature of CPPSs as potential drivers of the Fourth Industrial Revolution have already been demonstrated [1,8,18-20]. Real production scenarios have also been used to show how simulations, measurement tools, and campaigns can help to improve the energy 
and resource flows [21]. Nevertheless, the current research in this area raises the question of the extent to which digital solutions can help to achieve the environmental goals [15]. The framework developed by Thiede [15] offers the opportunity to assign digital solutions in a structured way that also includes information and communication technologies.

Furthermore, there are research contributions that refer to sustainable manufacturing systems (SMSs) that have a direct relation to the manufacturing aspect of sustainabilityoriented CPPSs, but that are not comparable in all areas. The comparability between SMSs and CPPSs arises from the production references and the shifted focus onto the sustainability-oriented operations within the system. Differences can be seen in the operations of the methods. The focus of a CPPS is clearly on the digitization of the production system in order to achieve the resulting benefits, while SMSs use a wide variety of methods from production and logistics without having the specific focus of Industry 4.0 or CPSs. For example, the simulation models for the correct composition and structure of SMSs are known. Here, the optimal compositions between the efforts and the benefits within the production system can be highlighted, which also relate to the energy consumption and the $\mathrm{CO}_{2}$ emissions [22]. In addition, there are known approaches for the strategic assessment of SMSs, which mainly refer to the risks and the simultaneous minimizations of these [23]. Therefore, economic and environmental aspects have been considered that have an impact on the elaborations of these systems, and that have a direct relation to the possible strategic development of a sustainability-oriented CPPS.

The approaches considered contribute added value to the elaboration of the strategic development of CPPSs. The literature already features a broad spectrum of environmental factors and their evaluations and incorporations into CPPSs. Even general production management methods can be related to sustainability in the manufacturing environment. However, these are typically strongly related to processes and, particularly with regard to the digitalization of production systems, can lead to further disadvantages in terms of the environmental sustainability because of the potential further use of resources. The existing approaches mostly address the subsequent evaluation of the environmental impacts of CPPSs. None of the solutions and models already developed in the field of sustainable manufacturing offer a consistent approach to supporting the development of sustainabilityoriented CPPSs in the early phase of the planning of a digitized manufacturing system.

To this end, a more systematic development, which is applied before the system is actually installed, is required. This development procedure considers the process parameters and the relevant variables, as well as their interrelationships, so that those parameters that really do have a great influence on the sustainable operation of a manufacturing system can be identified. Therefore, the measurement strategies, hardware (e.g., sensors), and process parameters have to be analyzed. To achieve this, a holistic methodical approach is necessary, which combines both the premises of the CPPS, and the guidelines of an environmentally sustainable approach.

\section{Methodological Approach}

Digital solutions and CPPSs can make positive contributions to improving the environmental impacts of manufacturing. To support the systematic development of sustainabilityoriented CPPSs, we propose a methodological approach, which is illustrated in Figure 3. The approach is intended to prevent the ill-considered and uncontrolled implementation of measurement strategies or hardware in CPPSs that may prove to be unnecessary or unimportant in retrospect. The methodological approach invokes the interactions between the basic construction of the variable relationships within a system, and the use of a correlation methodology, which, in this case, is described by the use of a cross-impact analysis, and the use of a CPPS. This results in a step-by-step approach that reveals the potential improvements for the system, especially with regard to the environmental aspects. This generic approach should be transferable to different application fields, such as conventional metalworking by machine tools, industrial additive manufacturing processes, 
or other production processes that have specific hardware requirements in production environments.

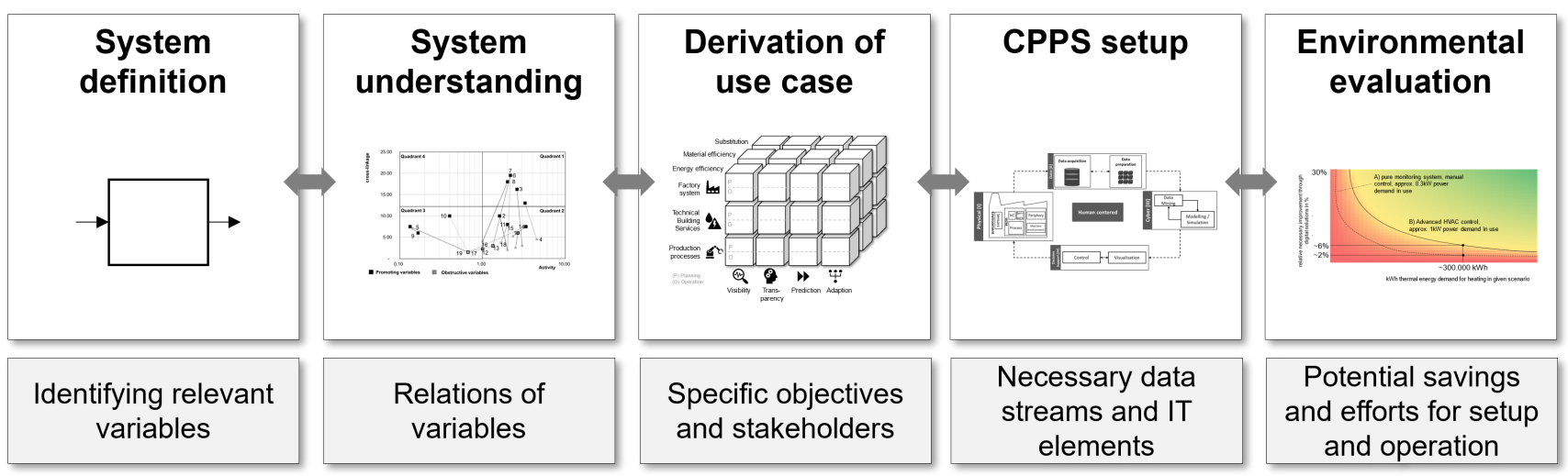

Figure 3. Methodological approach for a systematic development of a sustainability-oriented CPPS $[8,9,14,15]$.

The systematic approach is based on five steps, which ultimately result in a quantified comparison between, and evaluation of, the measurements of the relevant parameters and variables and the design of the technical system. These steps are:

1. The system definition to identify the relevant variables;

2. The system understanding, which allows for quantifying the relations between the identified variables;

3. The derivation of the use case to support the definitions of the objectives and the stakeholders involved in setting up a CPPS;

4. The CPPS setup, which defines the necessary data streams and the IT elements;

5. The environmental evaluation, which helps to calculate the potential savings and efforts for the setup and operation.

\subsection{System Definition}

In the first step, the system definition and the system boundaries of a considered cyberphysical environment are defined and analyzed. This requires the identification of all the variables of the system that are relevant to supporting the setup of a sustainability-oriented CPPS. These can include the manufacturing process variables, as well as the environmental variables of the overall system, and they can also include the procedural and already existing solutions within the system. These variables can be assigned to different groups of datasets. A distinction is made between the design and control parameters, the state variables, the performance criteria, and the external influencing factors (see Table 1) [8]. To support the identification of the variables, any type of effect diagram can be used (i.e., causal chain or causal loop diagrams) [24,25]. For example, in an effect diagram, the interrelations of the control parameters, the state variables, the performance criteria, and the external influencing factors can be illustrated qualitatively through a visual description. Here, the design and control parameters, as well as the state variables, are to be seen as the acting variables, whereas the performance criteria are the variables to be influenced. The external variables can have an effect on each of them and they are to be regarded as overlapping. The result of the first step is the clearly identifiable relationships of all the variables and the definitions of the relevant parameters and intervention variables, which find preferential consideration in the subsequent steps. Thus, all of those parameters that may have a greater influence on the environmentally sustainable operation of the system under consideration can be identified. 
Table 1. Groups of variables for CPPS [8].

\begin{tabular}{ccc}
\hline Type of Variable & Description & Example \\
\hline $\begin{array}{c}\text { Design and control } \\
\text { parameters }\end{array}$ & $\begin{array}{c}\text { Describe machine and process } \\
\text { characteristics for the product } \\
\text { and process side }\end{array}$ & $\begin{array}{c}\text { Product and process } \\
\text { parameters (e.g., cutting } \\
\text { speed) }\end{array}$ \\
\hline State variables & $\begin{array}{c}\text { Describe system behavior and } \\
\text { are typically not controllable }\end{array}$ & $\begin{array}{c}\text { Electrical power, vibrations, } \\
\text { noise, force }\end{array}$ \\
\hline Performance criteria & $\begin{array}{c}\text { Describe performance-related } \\
\text { variables, which are } \\
\text { influenced by the other } \\
\text { categories }\end{array}$ & $\begin{array}{c}\text { Environmental impact, } \\
\text { costs }\end{array}$ \\
\hline External influencing factors & $\begin{array}{c}\text { Describe all environmental } \\
\text { conditions and influences }\end{array}$ & Temperature, humidity \\
\hline
\end{tabular}

With the support of this first step, and the identification of the relevant parameters, transparency can be created in advance with regard to all of the variables to be included, as well as an awareness of the scope of the CPPS to be built.

\subsection{System Understanding}

By identifying the relevant parameters, these can then be put into the relationships in the second step. This step serves to create a system understanding and quantifies the general variable relationships. The relationships can be highlighted and evaluated within the procedure with the help of a cross-impact analysis.

In general, a cross-impact analysis is concerned with the prediction of properties or correlations using the perceptions on how future interactions might proceed or interact [26]. Basically, the cross-impact method is an analytical approach in which the probabilities, and, thus, the subjective perceptions, of groups or individuals in a predicted set are reflected. The events and evolutions identified in the cross-impact analysis, and the interrelationships that arise between them, are referred to as the "cross-impact" [26].

In Figure 4, the generic structure of a graphical evaluation of a cross-impact analysis is illustrated. The four quadrants divide the graph into the variable ranges, according to the activity ( $x$-axis) and the cross-linkage ( $y$-axis).

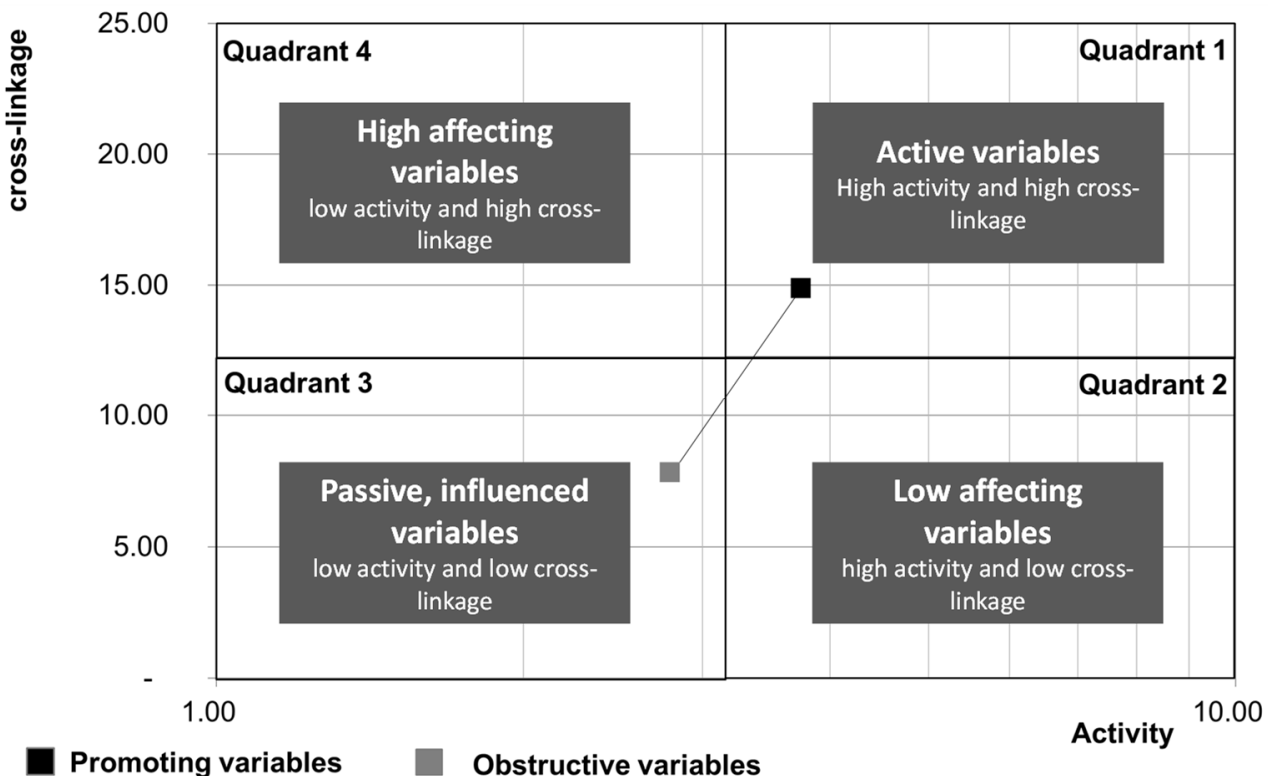

Figure 4. Generic structure of a cross-impact analysis [27]. 
A distinction is made between very active variables, with high degrees of interconnectivity (Quadrant 1), and low-affecting variables (Quadrant 2), which generally lose importance for the system because of their low degree of cross linking and passively influenced variables (Quadrant 3), which generally determine the performance factors of the system under consideration, and the high-affecting variables (Quadrant 4), which have a high leverage effect on the other variables. A generic illustration of an exemplary variable can be seen in the center of the figure. The dependencies of a variable are indicated by the two ends of the link, which makes it possible to identify the supporting and obstructive effects of the variable. In the approach presented here, the cross-impact analysis serves as a methodological approach to predict the probabilities of the relationships in a manufacturing system [26]. Taking the subjective perception into account, and considering the influences of the different variables on each other, the ratios are presented in matrices [28]. The analysis allows for the determination of exactly those variables and structures of the system that may have increased impacts on the environmental sustainability of the CPPS, and it thus provides a first assessment of the possible consequences or potentials within the implementation. The cross-impact analysis can draw on the predefined context of each relevant variable and can clearly highlight the relationships. The goal of the application is to compare the individual recommendations for each action to the necessary measurements on the physical level of the CPPS. Both the actively influencing variables and the passive variables of the system can be identified and can be put into quantifiable relationships.

\subsection{Derivation of the Use Case}

The third step of the methodology is the definition of the intended use case of the CPPS. For this purpose, the information from the first two steps of the procedure is essential to identifying or defining the specific goals of the digital solution. In this step, the variables can be linked to the technologies and the production environment. For the evaluation, selection, and goal setting of the overall system, a consistent assessment procedure is necessary, which addresses both the individual areas of the sustainability orientation, as well as the factory and production conditions [15].

Thiede already combines an approach for deriving the use case in digital solutions, as well as the explained specific development of the use case for the known variables in this elaboration, which is illustrated in Figure 5 [15].

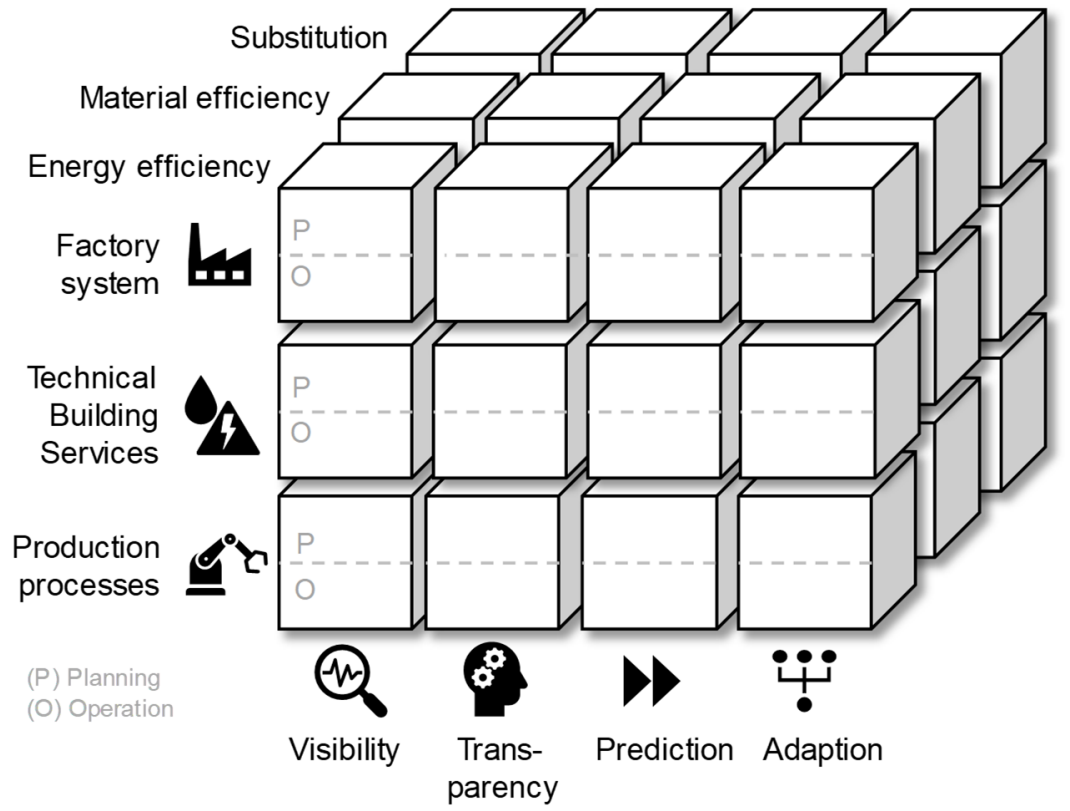

Figure 5. Illustration of the use-case description [15]. 
The maturity levels of digital solutions (visibility to adaption) are shown on the basis of the fields of application within a factory (production level to a whole factory system) in relation to the fields of action for a sustainability-oriented system (energy efficiency, material efficiency, or substitution). The different maturity levels show an increasing complexity, but they also show greater benefits [15]. The specific use case is formed within the boxes for each individual area of each rising level on a planning or operations basis $(\mathrm{P} / \mathrm{O})[15]$.

Thus, the use case can already be related to specific solution ideas and can be developed specifically from the known variables of the previous steps.

\subsection{CPPS Setup}

Once the application scenario is known and the variables have been quantified, the CPPS is conceptualized, and it must have the necessary information technology elements and data strings to measure the relevant parameters and variables and transfer them into the cyber world. The measurement strategy, which results from the parameter identification of the cross-impact analysis, as well as the requirements from the use case, can be linked with the suitable hardware and sensor technologies as part of the physical world in the CPPS. This specified hardware implies that only the data that are really necessary for the use case of the CPPS are recorded, and it thus contributes to a sustainability-oriented CPPS. Through data acquisition and preparation, these variables (Table 1) can be recorded with a high resolution and can be processed and stored in suitable databases [9]. In this step of the approach, it is necessary to infer the correctness of the results. Therefore, the already known parameters and the necessary hardware are related. Furthermore, targeted modeling and simulation approaches can be developed. For this purpose, existing machine learning algorithms or different types of simulations (i.e., static, multiagent-based) can be utilized. This results in visualization and direct feedback loops to adapt the physical world to more sustainable behavior in terms of the decision support and control of the CPPS.

\subsection{Environmental Evaluation}

The final element of the systematic approach is the environmental evaluation of the CPPS. The core of this evaluation is the elaboration of the potential savings and expenses from an environmental perspective. To this end, the basic, as well as the extended factors of the resulting CPPS are compared on the basis of an environmental assessment. The environmental impact (EI) (measured in $\mathrm{kg} \mathrm{CO}_{2}$ ) of the CPPS is added as an evaluation factor [9]. For this purpose, both the energy and material consumption of each individual component is considered and included in the EI. This is then used to obtain a comparison between the negative (environmental backpack) and the necessary positive (payback) impacts of the CPPS. Feasibility diagrams can be used to graphically represent this comparison and can provide decision support [9].

On the basis of the analysis, feasibility diagrams, as mentioned in Section 2.2, can be used for an evaluation [9]. In general, these diagrams allow for a comparison between the environmental impact of the CPPS and the improvements brought about by the digitization. Thus, the extent to which the elaborated solution actually reduces the environmental impact of the CPPS can be clearly quantified. In addition, the assessment can indicate the minimum level of savings that must be achieved through the deployment of infrastructure and resources in order to have a real positive impact on the CPPS built over time. Accordingly, these statements can be made in relation to the environmental criteria that were defined in advance in the selection and derivation of the use case and the quantified variable relationships.

An exemplary and generic feasibility diagram is shown in Figure 6. The environmental impacts of the considered solution are shown on the abscissa, and the potential necessary savings, or efficiency increases, of the system are shown on the ordinate. The shaded areas of the diagram indicate the break-even points of the comparison, while the trajectory of the curve exemplified here is derived from the environmental backpack, which is calculated by 
the additional components. In order to indicate the necessary improvements, the solutions can be marked on the curve trajectory.

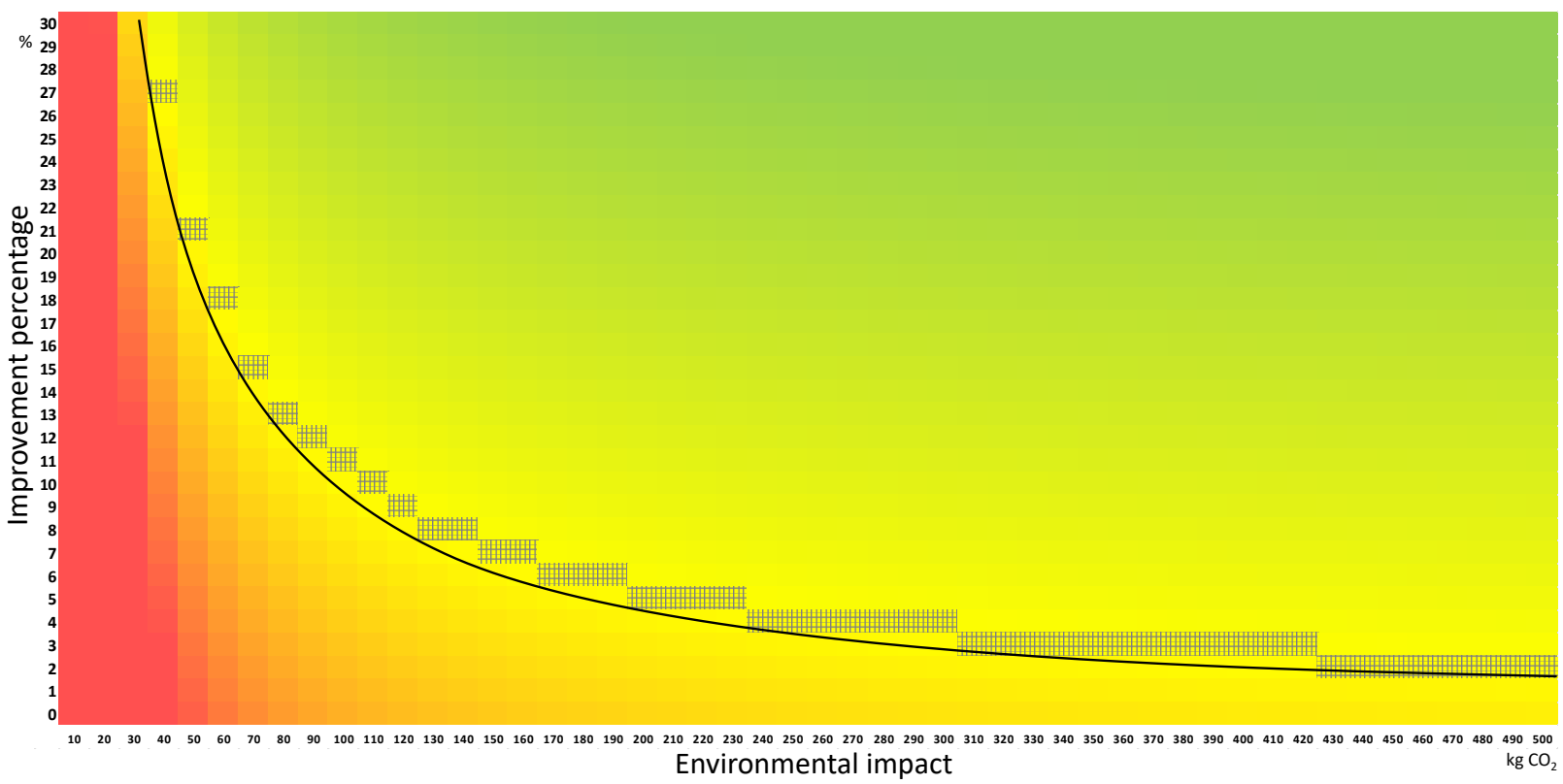

Figure 6. Feasibility diagram to support the environmental evaluation of sustainability-oriented CPPSs [9].

The procedure supports the systematic development of sustainability-oriented CPPSs as a generic approach for technical-use cases, and it allows for a consideration of the variable environmental and economic factors in the evaluation. The methodology serves as a start for a more sustainable digitalization. In the following, it is transferred into a use case and applied in order to support a better understanding of the approach.

\section{Case Study}

In this section, the methodological approach is applied to an exemplary operating scenario in 3D printing. The focus of the use case is not on a complete technical recording of the variable relationships, hardware, or measurement strategies, but on the implementation and transfer of the approach. Therefore, the individual steps shown are presented schematically to illustrate an exemplary procedure for developing a sustainability-oriented CPPS, but there is no claim to completeness (e.g., of the variables).

Accordingly, in the following, a systematic development of a CPPS for the 3D-printing use case is performed using the presented methodology, and any improvements and environmental/economic potentials are identified.

The 3D printer for this use case is a Prusa i3 MK3S (Prusa Research a.s., Prague, Czech Republic), which can be described as a nonindustrial home-based 3D printer. Only plastic filament use is possible. The printer serves as a simple entry case for testing the methodological approach because of the low level of complexity of the application. However, even with this type of 3D printer, the scientifically known parameters and the variables from the industry are applicable and changeable.

\subsection{System Definition}

The system definition of the 3D printer refers to the identification of the relevant variables of the system. In this context, the causal chain analysis is used, which is a simplification of the causal loop method (see Section 3) and is based on the root cause analysis [29]. Within the analysis, all of the variables and the influences on the system are listed, and, in the second step, the mutual correlations are determined through a rough 
estimation. Figure 7 shows the causal chain diagram of the use case. The categories explained in Section 3 support the classification of the variables in this step.

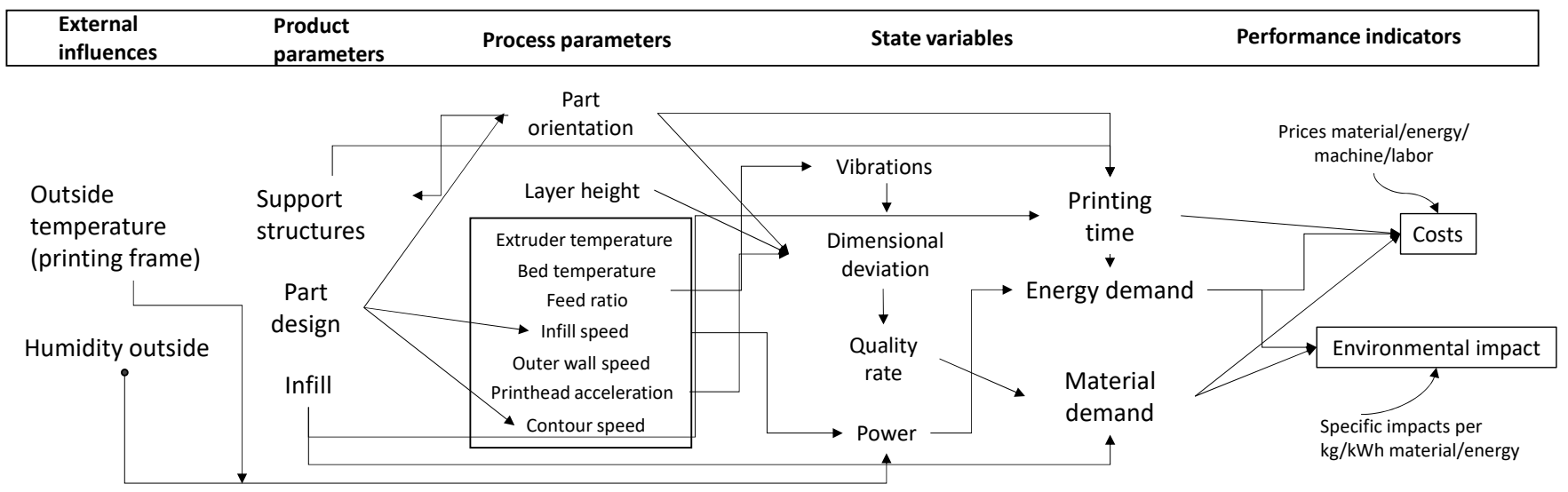

Figure 7. Causal chain of the 3D-printing use case.

In the beginning, the basic performance indicators of the system can be defined, which, in this case, are the costs (economic perspective) and the environmental impacts (ecological perspective). These indicators show the basic direction of the causal development and they are adopted for this use case as benchmarks for the sustainability-oriented development of the system.

As a link between the performance indicators and the state variables, and as the second main group of variables, the environmental consumption and the printing time are considered. The state variables serve as a means of deriving an indirect dependency between the technical printer parameters, the costs, and the environmental impact, without solely referring to the printer consumption per se. The state variables refer to variables that do not arise directly from the printer parameters and that basically require external measuring devices (e.g., power or vibrations), but that naturally have dependencies. These state variables are typically not directly controllable. Furthermore, the process parameters (temperatures, infill, speeds, and layer height), as well as the product parameters (support structures, component design, etc.), are mapped in the analysis. The fifth main group includes the external influences on the printer, which relate to, for example, the outside temperature and the humidity. By means of the concrete listing and the first rough comparison of the variable types and parameters, the correlations and the possible influences are already recognizable. This can support the identification of the relations to the performance indicators. In this case, the causal chain analysis is preceded by a list of fundamentally relevant 3D-printing parameters, which require expertise in the field.

\subsection{System Understanding}

In the next step of the procedure, it is necessary to quantify the relations and correlations of the system from the causal chain analysis. This quantification is conducted by using a cross-impact analysis.

For the use case, the cross-impact analysis is applied in two ways [27,30]. The first matrix (encouragement) shows the promoting interdependencies, and the second matrix shows the hindering (constraints) interdependencies of the variables for a sustainabilityoriented structure of the CPPS. The evaluation within the matrix is produced by the following steps: "0—no influence"; " $0.5-$ low influence"; " 1 -medium influence"; and "2-strong influence" [27], meaning that an influencing variable has no influence, or low, medium, and strong influences on the altitude of the influenced variable. After completing the comparison of the two matrices, a cross-linkage diagram can be created. The values within the cross-linkage diagram are the result of the products and quotients of the 
individual values within the rows and columns from the two cross-impact analyses [27,30]. The cross-linkage analysis of the 3D-printing use case is presented in Figure 8.

\begin{tabular}{|c|c|}
\hline Variable from causal chain & Matrix number \\
\hline extruder temperature & 1 \\
\hline bed temperature & 2 \\
\hline layer height & 3 \\
\hline infill & 4 \\
\hline power & 5 \\
\hline outer wall speed & 6 \\
\hline contour speed & 7 \\
\hline infill speed & 8 \\
\hline printing time & 9 \\
\hline vibrations (xyz) & 10 \\
\hline humidity outside & 11 \\
\hline material usage & 12 \\
\hline support structures & 13 \\
\hline printhead acceleration & 14 \\
\hline feed ratio & 15 \\
\hline part orientation & 16 \\
\hline part design & 17 \\
\hline dimensional deviation & 18 \\
\hline & 19 \\
\hline
\end{tabular}

(a)

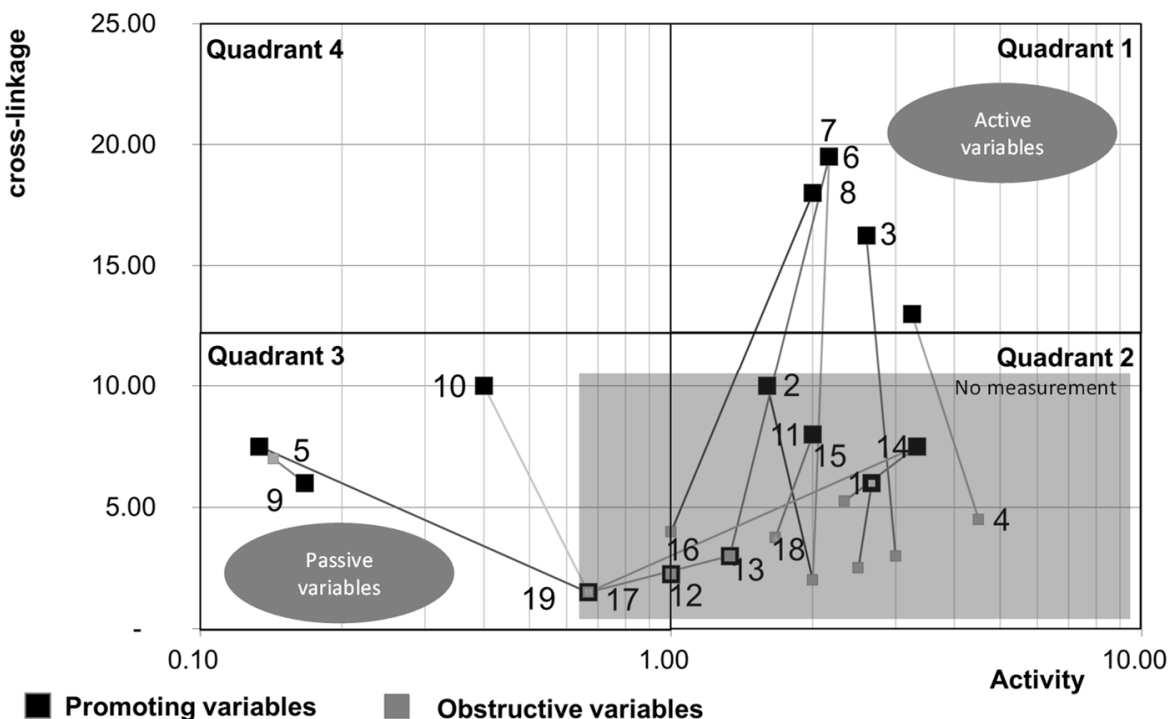

(b)

Figure 8. (a) Variables for the cross-linkage analysis in 3D-printing use case; (b) cross-linkage analysis in 3D-printing use case [27].

The presented cross-linkage analysis (Figure $8 b$ ) shows the interdependencies of the 19 defined variables (Figure 8a), which can have meaning for, or an influence on, the construction of a CPPS in the 3D-printing application case. In the cross-linkage analysis, the $x$-axis represents the activity of the variable in relation to the total influence exerted. The $y$-axis illustrates the cross-linkage of the variable, i.e., the interconnectedness of the variable. The higher the cross-linkage in the application, the more important the variable is for a possible measurement because of its large influence on the passive variables (activity value < 1) [27].

On the basis of the division of the diagram into four quadrants, the variables can be classified according to their significance and their leverage on the environmental and economic impacts on the CPPS. Thus, the first quadrant denotes those variables that have high activity and a high number of cross-linkages (highlighted in Figure 8a). These variables are to be classified as "absolutely to be measured", and they have a very large influence on the passive variables. In the second quadrant, there are mainly variables that show high activity, but that tend to have only a few dependencies because of a lower number of cross-linkages. Therefore, these variables only require sensing or detailed measurements in the CPPS in exceptional cases. Although the variables of the third quadrant show relatively low activity and low numbers of cross-linkages, these variables precisely target the resulting performance indicators (highlighted in Figure 8a). Therefore, these variables need to be measured in order to determine the actual influence of the variables from the first two quadrants, as they have a very high influence on the sustainability orientation of the CPPS and are easily influenced by fluctuations in the system (Figure 7). The fourth quadrant, which is not occupied in this case, shows variables that provide high levels of feedback to the overall system, and that, similar to Quadrant 1, must be measured absolutely because of their high influence and influenceability.

\subsection{Derivation of Use Case}

The derivation of the use case can now be carried out specifically for the building of the CPPS using the example of the 3D printer. For this purpose, the results of the system 
definition and the system understanding are bundled and transferred into a targeted CPPS use case. The goal of this use case is to evaluate and improve the environmental sustainability, as well as the process conditions, of a conventional plastic 3D printer by a CPPS. The requirements for the CPPS are related to the transparency of the process, as well as to the evaluation of the environmental factors, which are related to the energy and the material efficiency.

Therefore, on the basis of the cross-linkage analysis, it only makes sense to convert the variables from Quadrants 1 and 3 into actual measurements. The marked process parameters and the variables result from Figure 8a. The process parameters are located in the first quadrant and they denote the core settings in a conventional plastic 3D-printing process. The infill, the layer height, and the speeds are essential parameters that influence the performance of the printer, as well as the material requirements and the time, and are therefore also variables with a high influence density for the development of a sustainabilityoriented CPPS. The printing time, the vibrations in the process, and the performance of the printer are parameters that can be easily influenced in the third quadrant, but that have a high effect on the cross-linkage of the use case. Figure 7 shows that it is exactly these parameters that are directly linked to the performance indicators (costs and environmental impact) via the quality, the energy, and the material requirements. Therefore, in this application, it is necessary to integrate a technical system into the CPPS at the physical level, including the necessary sensors for measuring these parameters, in order to minimize the environmental impact on the CPPS.

\subsection{CPPS Setup}

Similar to the conventional structure of a CPPS described in Section 2.1, the structure of the physical layer is adapted in the fourth step of the systematic development. On the basis of the previous investigations and findings, this level comprises the 3D printer as the reference to a production machine, as well as various measurement equipment in the form of hardware and sensors. The required sensor technology was determined in this use case on the basis of the requirements resulting from the objectives and the cross-linkage analysis, and it is therefore tailored to a sustainability-oriented type of development. The resulting variables to be measured are, on the one hand, process-related (layer height, infill, speeds), and are, on the other hand, condition-related (power, printing time, vibrations). The resulting CPPS, with a focus on the physical layer, is shown in Figure 9.

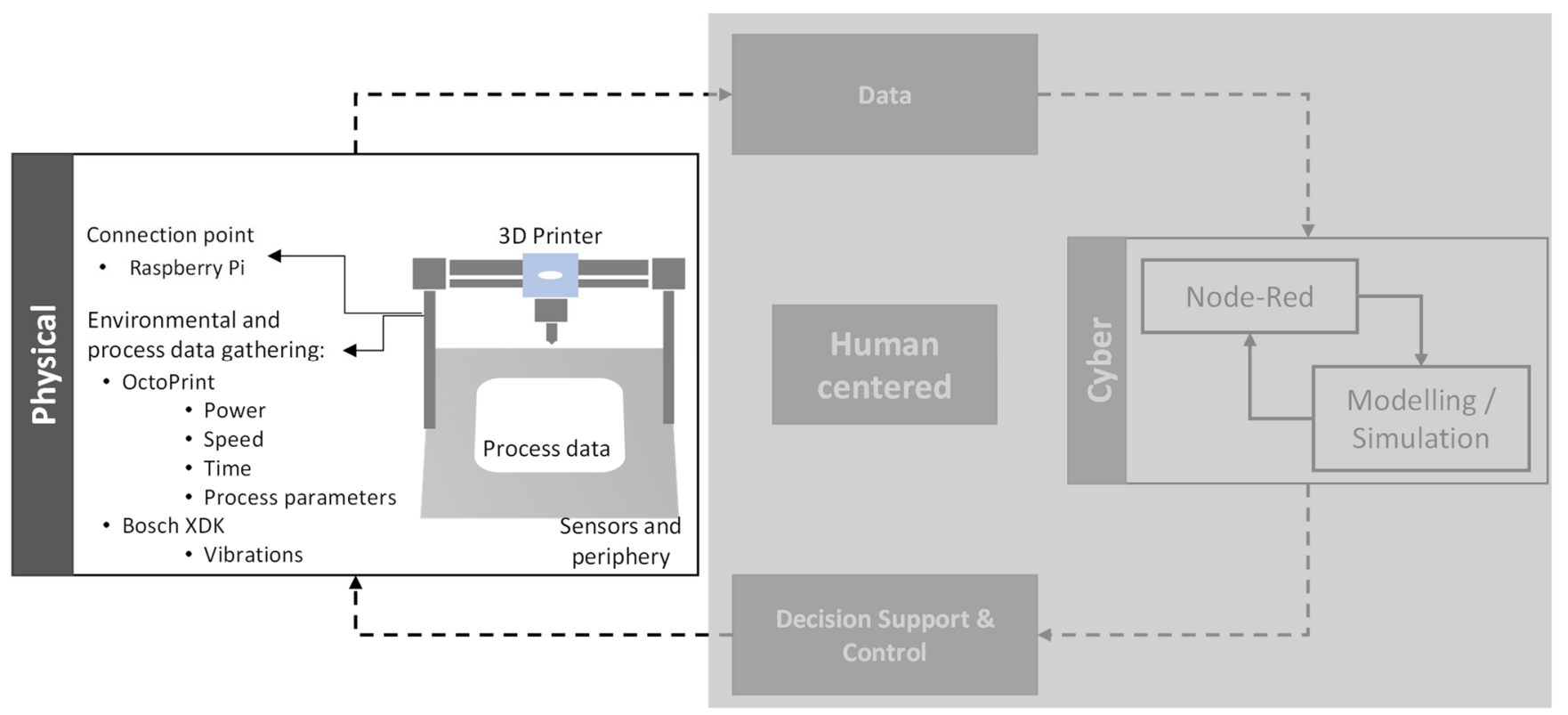

Figure 9. CPPS setup for the use case with a focus on the physical layer [10,31-33]. 
The technical measurement system results from the explained variables. OctoPrint version 1.7.2 (Octoprint, Obertshausen, Germany) software was used to measure the printing parameters [31]. The software provides an open-source format and is developed specifically for 3D printing. All G-code data can be viewed and forwarded via Message Queuing Telemetry Transport (MQTT) for data processing. In this case, the software is installed on a Raspberry Pi (Raspberry Pi Ltd., Cambridge, United Kingdom) and is permanently connected to the printer. A Bosch XDK (Robert Bosch $\mathrm{GmbH}$, GerlingenSchillerhöhe, Germany) is used as the sensor system for measuring the vibrations in the process [32]. This sensor node, which is to be understood as a "low-cost" solution, can also be connected via MQTT to a broker for data forwarding, and it records the vibrations on the printer frame in this application. The particular advantage of this solution is that the sensor node has low recording power, but, especially in the future, and if necessary and after re-evaluation, further measurements are possible through the sensor node and can be added. A second Raspberry Pi was used as the linking point of the overall system, which serves as the MQTT broker and database. For the data processing of the OctoPrint and the XDK data, the software, Node-RED version 2.1 (Node-RED, OpenJS Foundation \& Contributors), was used [34]. This low-code programming environment for event-based applications was chosen for its versatility and connectivity.

The CPPS was developed on the basis of the defined methodological procedure and it thus consists of the necessary components for the measurement and the 3D printer itself. Whether the development of the CPPS with the assistance of the generic methodology actually results in an improvement of the environmental impact must be determined in the final step. However, a major advantage of the systematic development of sustainabilityoriented CPPSs has already been achieved at this point through the selection of the suitable variables and measurement strategies that contribute precisely to the achievement of the goal.

\subsection{Environmental Evaluation}

The environmental evaluation of the developed CPPS is performed on the basis of a feasibility diagram, as was already described in Section 3. The aim of the diagram is to compare the environmental impact via the $\mathrm{CO}_{2}$ equivalent $\left(\mathrm{kg} \mathrm{CO}_{2}\right)$ of the CPPS to the necessary improvements in the system. Accordingly, the $\mathrm{CO}_{2}$ equivalent is illustrated on the $x$-axis, and the percentage influence of the added measurement and sensor components are illustrated on the $y$-axis. Therefore, the break-even point of the introduced additional components within the CPPS, illustrated by the isopleths, is considered.

In this use case, two Raspberry Pis and one XDK sensor node were added to the physical layer to meet the measurement requirements. This corresponds to a measurementside power consumption of $10.5 \mathrm{~W}$. The 3D printer under consideration has a power consumption of $120 \mathrm{~W}$. For the material usage, an ABS filament consumption of $52 \mathrm{~g} / \mathrm{h}$ is assumed. A production volume of $8 \mathrm{~h}$ for 250 days per year is assumed as a comparison scenario in this case, so that the printer operates $2000 \mathrm{~h}$ per year in this CPPS application scenario. The calculation of the $\mathrm{CO}_{2}$ equivalents for this evaluation can be found in Table 2 .

Table 2. Evaluation of $\mathrm{CO}_{2}$ equivalents [35-37].

\begin{tabular}{|c|c|c|}
\hline 3D Printer & Material Demand & Sensor and Technical Equipment \\
\hline Energy-240 kWh & Material usage $-103.68 \mathrm{~kg} / \mathrm{y}$ & Energy-0.0105 kWh \\
\hline Energy mix-0.5 $\mathrm{kg} \mathrm{CO} 2 \mathrm{eq} / \mathrm{kWh}$ & $\mathrm{CO}_{2}$ footprint material-3.46 $\mathrm{kg} \mathrm{CO} 2 \mathrm{eq}$ & Energy mix- $0.5 \mathrm{~kg} \mathrm{CO} 2 \mathrm{eq} / \mathrm{kWh}$ \\
\hline $\mathrm{CO}_{2}$ footprint- $120 \mathrm{~kg} \mathrm{CO} 2 \mathrm{eq}$ & $\mathrm{CO}_{2}$ footprint-358.73 $\mathrm{kg} \mathrm{CO} \mathrm{CO}_{2 \mathrm{eq}}$ & $\begin{array}{l}\mathrm{CO}_{2} \text { footprint-10.94 } \mathrm{kg} \mathrm{CO}_{2 \mathrm{eq}} \\
\left(\text { Material-0.22 } \mathrm{kg} \mathrm{CO}_{2 \mathrm{eq}}\right)\end{array}$ \\
\hline
\end{tabular}

Assumptions have been made for the sensory and entire technical equipment, due to data inaccuracy, for any content components. For the sensory hardware, it should also be mentioned that the material impact, which was estimated on the basis of the 
literature data [35-37] and experience, accounts for $2 \%$ of the $\mathrm{CO}_{2}$ footprint of the installed information technology elements, and would, therefore, be rather negligible in comparison to the energy consumption.

Figure 10 presents the feasibility diagram resulting from these calculated $\mathrm{CO}_{2}$ equivalents. The diagram (Figure 10) indicates the necessary energy and material efficiency improvements needed in the CPPS in order to reach an environmental breakeven.

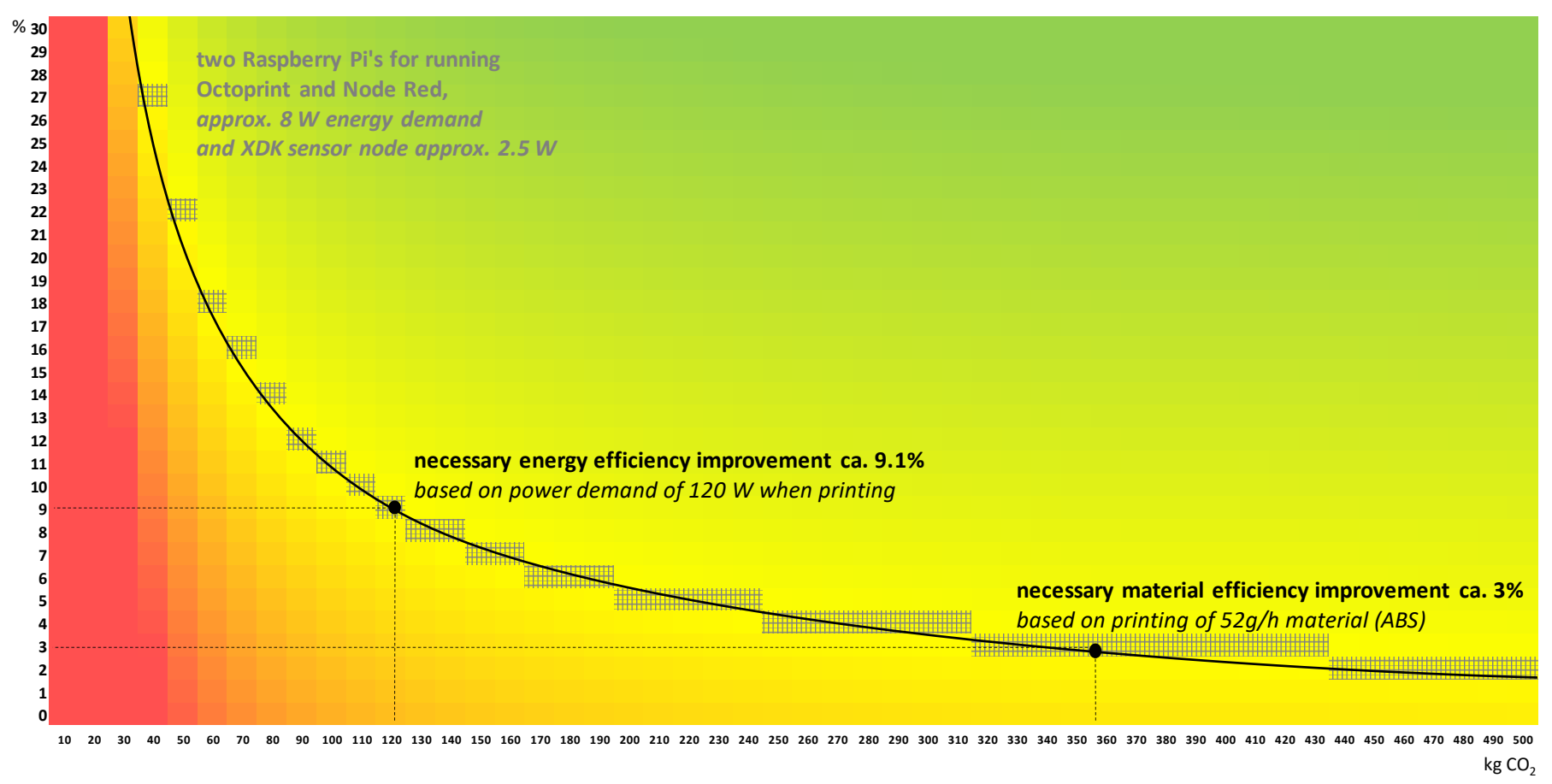

Figure 10. Environmental evaluation of the developed CPPS [15].

The introduction of the CPPS components into the setup requires an increase in the energy efficiency of $9.1 \%$, which is generated not only by the additional energy consumption, but also by the total $\mathrm{CO}_{2}$ footprint. The material consumption within the production is significantly higher, and a lower efficiency increase of $3 \%$ is necessary in this case to compensate for the footprint of the sensory and technical equipment. There are numerous possibilities for obtaining these improvements. For example, the necessary $9.1 \%$ or $3 \%$ increases in the energy and material efficiencies, respectively, can be achieved by reducing waste, predictive measures for maintenance, or by process optimization on the basis of the more transparent data situation. In principle, the results of the feasibility diagrams with regard to the production background, especially the percentage comparison, should always be considered in relation to the application. Energy-intensive machine applications, such as conventional metalworking processes, would require a significantly lower increase in the efficiency for the same hardware input, in terms of the energy and the associated $\mathrm{CO}_{2}$ impact, because of their already high-energy input. Nevertheless, even in this example, the potentially increased use of resources and the associated conditions must be taken into account.

More insertions of technical equipment or CPPS components would further increase the environmental impact of the CPPS. Therefore, the introduction of conventional CPPS components, such as a laptop instead of the Raspberry Pi, would make an increase in the total efficiency of the system by the introduction of the CPPS more difficult. By contrast, the use of, e.g., only one Raspberry $\mathrm{Pi}$, could improve the balance and efficiency of the system. Furthermore, the introduction of additional sensory components or measurement devices into the system without the application of the methodological approach would lead to a higher environmental backpack. This can only be prevented or minimized with the help of the precise selection of variables and values to be measured. Without this approach, the 
relevant variables could not be identified, and the curve (Figure 10) would continue to increase with each additional component at the physical level of the CPPS, thus requiring higher percentages in the energy and material efficiencies of the system.

In principle, the evaluation proves that the systematic development of a CPPS as an overall system can provide insights into the environmental sustainability of CPPSs. The targeted development and selection of the CPPS components, architecture, and dimensioning are essential for the sustainability-oriented design of CPPSs. The selection of particularly important and strongly integrated variables and process parameters creates transparency even before the actual construction of the CPPS, and contributes not only to sustainable development alone, but also to savings in time and effort, and to process knowledge.

\section{Conclusions}

The paper addresses the systematic development of sustainability-oriented cyberphysical production systems, with the help of a methodological approach, which is based on cross-impact and cross-linkage analyses. A clear definition and understanding of the overall system under consideration is supported by the methodological approach, which identifies the relevant variables and process parameters, and which allows for the selection of the appropriate sensor technology. This enables the experimental setup to be reflected from a sustainability-oriented perspective. By means of an evaluation through feasibility diagrams, the additional environmental backpack integrated into the system can be shown and the efficiency improvement requirements can be quantified. Within a case study, the technical environment of a 3D-printing device as a CPPS was illustrated to show the potentials of the approach. This helped to define a minimally invasive strategy for the development of the required CPPS.

The presented use case shows only one possibility for using the methodology and is used as an example. It should prove the feasibility of the systematic development of a sustainability-oriented CPPS. The results of the evaluation show clear potentials for the predimensioning and variabilization of a CPPS, so that the procedure can be transferred to various application areas and digital solutions.

By creating a generic approach, it is possible to estimate which data and variables are needed to support sustainability-oriented CPPSs, and how this can minimize unreflective data collection in industrial-use cases. Similarly, it is essential to be able to determine those variables that have greater impacts on sustainability in production. The link between the important variables and the right sensor technologies and hardware is thus indispensable for the sustainability-oriented design of CPPSs.

However, the selection of the relevant variables and the more environmentally sustainable CPPS that results, as a whole, does not allow any statements to be made about the achievability of the necessary energy or the material efficiency of the newly emerging system. Because of the introduction of new technical components into the system, and the evaluation of the environmental impact by the presented methodological approach, statements can be made about the necessary improvements to be achieved through the establishment of the CPPS, but further analysis and applications on the cyber level are required in order to be able to achieve these necessary percentage improvements. Nevertheless, these necessary efficiency improvements could be minimized by the provision of the methodical procedure, since significantly higher requirements would have to be made if a CPPS was set up in an uncontrolled manner.

Moreover, even though the methodological approach is generic and is thus transferrable to other use cases, the procedure should be adapted and evaluated for industrialuse cases, such as the design of a CPPS for machine tools, or whole production plants in general. Similarly, the focus on the social and economic aspects of sustainability for CPPSs can be strengthened in future implementations.

Author Contributions: Conceptualization, C.R., M.M. and S.T.; methodology, C.R., M.M. and S.T.; validation, C.R., M.M. and S.T.; writing-original draft preparation, C.R.; writing-review and editing, M.M., S.T. and C.H.; visualization, C.R., M.M. and S.T.; supervision, M.M., S.T. and C.H.; 
project administration, C.H.; funding acquisition, C.H. All authors have read and agreed to the published version of the manuscript.

Funding: The authors gratefully thank the Federal Ministry for Economic Affairs and Climate Action for supporting this work in the project "E-KISS" (Project number 03EN2037A).

Institutional Review Board Statement: Not applicable.

Informed Consent Statement: Not applicable.

Data Availability Statement: Not applicable.

Acknowledgments: We acknowledge support by the Open Access Publication Funds of Technische Universität Braunschweig.

Conflicts of Interest: The authors declare no conflict of interest.

\section{References}

1. Schuh, G.; Anderl, R.; Dumitrescu, R.; Krüger, A.; ten Hompel, M. (Eds.) Industrie 4.0 Maturity Index: Managing the Digital Transformation of Companies; The acatech STUDY Series; Herbert Utz Verlag: Munich, Germany, 2017; 60p, Available online: https: //www.acatech.de/wp-content/uploads/2018/03/acatech_STUDIE_Maturity_Index_eng_WEB.pdf (accessed on 24 November 2021).

2. Herrmann, C.; Schmidt, C.; Kurle, D.; Blume, S.; Thiede, S. Sustainability in manufacturing and factories of the future. Int. J. Precis. Eng. Manuf.-Green Tech. 2014, 1, 283-292. [CrossRef]

3. International Science Council. Digitalization and Sustainability-International Science Council. Available online: https://council. science/actionplan/digital-sustainability / (accessed on 29 November 2021).

4. Kagermann, H.; Wahlster, W.; Helbig, J. Forschungsunion Wirtschaft und Wissenschaft. In Im Fokus: Das Zukunftsprojekt Industrie 4.0; Handlungsempfehlungen zur Umsetzung; Bericht der Promotorengruppe Kommunikation; Forschungsunion: Berlin, Germany, 2012; 52p. (In Germany)

5. Kang, H.S.; Lee, J.Y.; Choi, S.; Kim, H.; Park, J.H.; Son, J.Y.; Kim, B.H.; Noh, S.D. Smart manufacturing: Past research, present findings, and future directions. Int. J. Precis. Eng. Manuf.-Green Tech. 2016, 3, 111-128. [CrossRef]

6. Arcot, R.V. Cyber-Physical Systems: The Core of Industry 4.0. Available online: https://blog.isa.org/cyber-physical-systems-thecore-of-industry-4.0 (accessed on 29 November 2021).

7. Andelfinger, V.P.; Hänisch, T. (Eds.) Industrie 4.0: Wie Cyber-Physische Systeme Die Arbeitswelt Verändern; Springer Gabler: Wiesbaden, Germany, 2017; 280p. (In Germany)

8. Thiede, S.; Juraschek, M.; Herrmann, C. Implementing Cyber-physical Production Systems in Learning Factories. Procedia CIRP 2016, 54, 7-12. [CrossRef]

9. Thiede, S. Environmental Sustainability of Cyber Physical Production Systems. Procedia CIRP 2018, 69, 644-649. [CrossRef]

10. Kumar, R.; Rogall, C.; Thiede, S.; Herrmann, C.; Sangwan, K.S. Development of a Decision Support System for 3D Printing Processes based on Cyber Physical Production Systems. Procedia CIRP 2021, 98, 348-353. [CrossRef]

11. Meissner, H.; Aurich, J.C. Implications of Cyber-Physical Production Systems on Integrated Process Planning and Scheduling. Procedia Manuf. 2019, 28, 167-173. [CrossRef]

12. Baheti, R.; Gill, H. Cyber-physical Systems. The Impact of Control Technology, 1st ed.; Samad, T., Annaswamy, A.M., Eds.; IEEE Control Systems Society: New York, NY, USA, 2011; pp. 161-166.

13. Thiede, S. Cyber-Physical Production Systems (CPPS): Introduction. J. Manuf. Mater. Process. 2021, 5, 24. [CrossRef]

14. Leiden, A.; Herrmann, C.; Thiede, S. Cyber-physical production system approach for energy and resource efficient planning and operation of plating process chains. J. Clean. Prod. 2021, 280, 125160. [CrossRef]

15. Thiede, S. Digital technologies, methods and tools towards sustainable manufacturing: Does Industry 4.0 support to reach environmental targets? Procedia CIRP 2021, 98, 1-6. [CrossRef]

16. Li, W.; Alvandi, S.; Kara, S.; Thiede, S.; Herrmann, C. Sustainability Cockpit: An integrated tool for continuous assessment and improvement of sustainability in manufacturing. CIRP Annals 2016, 65, 5-8. [CrossRef]

17. Suvarna, M.; Yap, K.S.; Yang, W.; Li, J.; Ng, Y.T.; Wang, X. Cyber-Physical Production Systems for Data-Driven, Decentralized, and Secure Manufacturing-A Perspective. Engineering 2021, 7, 1212-1223. [CrossRef]

18. Vogt, M.; Schlichter, J.; Aschersleben, F.; Abraham, T.; Wolf, L.; Herrmann, C. Integration of cyber-physical HVAC systems in Incremental Manufacturing to improve Energy Efficiency and Air Quality. Procedia CIRP 2021, 104, 482-487. [CrossRef]

19. Wessel, J.; Turetskyy, A.; Wojahn, O.; Herrmann, C.; Thiede, S. Tracking and Tracing for Data Mining Application in the Lithium-ion Battery Production. Procedia CIRP 2020, 93, 162-167. [CrossRef]

20. Filz, M.-A.; Gellrich, S.; Turetskyy, A.; Wessel, J.; Herrmann, C.; Thiede, S. Virtual Quality Gates in Manufacturing Systems: Framework, Implementation and Potential. J. Manuf. Mater. Process. 2020, 4, 106. [CrossRef]

21. Wiese, M.; Leiden, A.; Rogall, C.; Thiede, S.; Herrmann, C. Modeling energy and resource use in additive manufacturing of automotive series parts with multi-jet fusion and selective laser sintering. Procedia CIRP 2021, 98, 358-363. [CrossRef] 
22. Parv, A.L.; Deaky, B.A.; Stasiak-Betlejewska, R. Sustainable manufacturing systems-A simulation model. IOP Conf. Series: Mater. Sci. Eng. 2021, 1009, 12045. [CrossRef]

23. Chand, M. Strategic assessment and mitigation of risks in sustainable manufacturing systems. Sustain. Oper. Comput. 2021, 2, 206-213. [CrossRef]

24. Kern, J. Ursache-Wirkungs-Diagramme erfolgreich einsetzen: Das Ishikawa-Diagramm in Theorie und Praxis, German Edition ed; Independently published, 2021; 58p. (In Germany)

25. Haraldsson, H.V. Introduction to System Thinking and Causal Loop Diagrams; Reports in Ecology and Environmental Engineering, Report 1:2004; Lund University: Lund, Sweden, 2004; 49p.

26. Gordon, T.J. Cross-Impact Method (AC/UNU Millennium Project, Futures Research Methodology); United Nations: Vienna, Austria, 1994; 18p.

27. Bergmann, L.; Mennenga, M.; Dröder, K.; Horch, F. Automotive Research Centre Niedersachsen. Research Concept for Sustainable Mobility in Metropolitan Areas. In Proceedings of the 17th CIRP Conference on Life-Cycle Engineering, Hefei University of Technology, Hefei, China, 19-21 May 2010.

28. Chao, K. A New Look at the Cross-Impact Matrix and its Application in Futures Studies. J. Future Stud. 2008, 12, 45-52.

29. Schreyer, M. Entwicklung und Implementierung von Performance Measurement Systemen, 2008th ed.; Deutscher Universitätsverlag: Wiesbaden, Germany, 2008; 376p. (In Germany)

30. Ninck, A.; Bürki, L.; Hungerbühler, R. Systemik. Vernetztes Denken in komplexen Situationen; Orell Füssli: Zurich, Switzerland, 2004; 236p. (In Germany)

31. OctoPrint, version 1.7.2; Web Interface for 3D Printer; Created and Maintained by Gina Häußge. 2012. Available online: https:/ / octoprint.org/ (accessed on 2 December 2021).

32. XDK-The Sensor X-Perience; Programmable Sensor Device and IoT Prototyping Platform with an Open SDK for Any Use Case; Robert Bosch GmbH: Gerlingen, Germany. Available online: https://developer.bosch.com/products-and-services/sdks/xdk (accessed on 2 December 2021).

33. Mennenga, M.; Rogall, C.; Yang, C.-J.; Wölper, J.; Herrmann, C.; Thiede, S. Architecture and development approach for integrated cyber-physical production-service systems (CPPSS). Procedia CIRP 2020, 90, 742-747. [CrossRef]

34. Node-RED, version 2.2.0; Programming Tool for Wiring Together Hardware Devices, APIs and Online Services. OpenJS Foundation: San Francisco, CA, USA, 2013; Available online: https:/ / nodered.org/ (accessed on 2 December 2021).

35. Winnipeg. Winnipeg Sewage Treatment Program, South End Plant. 2011. Winnipeg Website. Available online: https: / / www.winnipeg.ca / finance/findata/matmgt/documents / /2012/682-2012 / /682-2012_Appendix_H-WSTP_South_End_ Plant_Process_Selection_Report/PSR_rev\%20final.pdf (accessed on 6 December 2021).

36. Icha, P.; Lauf, T.; Kuhs, G. Entwicklung der Spezifischen Kohlendioxid-Emissionen des Deutschen Strommix in den Jahren 1990-2020; Umweltbundesamt: Dessau-Roßlau, Germany, 2021; 30p.

37. Jia, J.; Puri, I.; Wang, E. Life-cycle of Raspberry Pi A+. 2016. Design Life-Cycle Website. Available online: http:/ /www.designlifecycle.com/raspberry-pi (accessed on 6 December 2021). 